\title{
Examination of Tensile Strength and End Notch Flexure Properties of Unidirectional Basalt Fabric Reinforced Polymer Composites With and Without Addition of Biochar Filler
}

\author{
K.Mayandi , N.Rajini , S.Rajesh , M.Gopal Krishnan, N.Antony Rooth
}

\begin{abstract}
The effect of biochar filler (carbon particle) on the mechanical properties over the inter-laminar surfaces of basalt unidirectional fabric/polyester resin is going to be scrutinized using Mode II delamination method. The ENF (end notch flexure) specimen is fabricated using hand layup method. Here basalt fabric is synthesized using unsaturated polymer resin with the help of methyl ethyl ketone peroxide and cobalt naphthenate as a catalyst. Both specimens are manufactured with and without biochar conditions. The laminate length and width will be customized as per the required dimensions of the ASTM standard. The ENF specimens are tested using the universal testing machine and the strain energy released rate and displacement of each specimen are been measured. The biochar based laminated composite has a resistant towards the fracture developed on laminated composite during testing due to the addition of carbon particles.
\end{abstract}

Keywords: Unidirectional basalt fabric, Tensile strength, ENF (End Notch Flexure), BioChar(BC),

\section{INTRODUCTION}

Composite materials are result of amalgamation of two or more materials constituting of different physical and chemical properties; when combined together form a different material with a new physical and chemical composition of its own in order to achieve desired properties such as strength, stiffness, reduced weight etc.,[1-4]. These materials are observed to remain isolated from each other and distinct thus making it separate from each other.

Revised Manuscript Received on December 15, 2019.

* Correspondence Author

Dr.K.Mayandi*, Mechanical Engineering Department, Kalasalingam Academy of Research and Education, Virudhunagar, India. Email: k.mayandi@gmail.com.

Dr.N.Rajini, Professor, Mechanical Engineering Department, Kalasalingam Academy of Research and Education, Virudhunagar, India. Email: rajiniklu@gmail.com.

Dr.S.Rajesh, Mechanical Engineering Department, Kalasalingam Academy of Research and Education, Virudhunagar, India. Email: s.rajesh@klu.ac.in.

M.Gopala Krishnan and N.Antony rooth, UG Students, Mechanical Engineering Department, Kalasalingam Academy of Research and Education, Virudhunagar, India. Email: santhoshiyer38@gmail.com.
The speciality of the composite material is that it has high strength and stiffness with low density and reduced weight. The matrix constituent used here in this work is basalt fabric. This polymer matrix composite is prepared in order to distribute loads between the fibres [5-7].

Delamination can be said as the isolation of laminated layers of a material. The mechanical properties of the laminated material get partially delaminated due to separate layers. Delamination may seem to be a very major issue in the concern of composite material as it degrades the quality being of a material. There are many methods which have been practically applied to scrutinize the characteristics of delamination [8-10]. On that basis, the delamination initiation and development of crack in the surface of specimen is going to be examined. Delamination occurs in a composite structure when the applied stress exceeds the designed stress and if the material is peregrinated from one place to another place [11- 12]. The mode II interlaminar fracture analysis of the Basalt/polyester composite is studied using flexural testing machines. Damage of the composite materials involves the delamination-initiated cracks in the laminar surfaces which often grow and de-enhances the quality of the material. This characteristic of delamination has been documented in several studies such as low-velocity impact, debonding and in non- unidirectional material when subjected to the condition of shear. So, delamination may be considered as one of the major reason due to which fiber composite's application is possessed. This work majorly focuses on the initiation of crack when the composite is delaminated. In this work, study of the delamination of basalt laminate polymer composite has been described. The delamination is being carried out by mode II interlaminar fracture analysis. Thus, in this work the bio char is been added to the unsaturated polyester resin in order to enhance the mechanical properties of the laminate polymer composite and to make the material to increase the resistance towards delamination. Interlaminar fracture toughness is the property of a composite material which often characterizes about the resistance towards the delamination in concern of energy release rate and critical strain energy release rate $(\mathbf{G c})$. 


\section{Examination of Tensile Strength and End Notch Flexure Properties of Unidirectional Basalt Fabric Reinforced Polymer Composites With and Without Addition of Biochar Filler}

Thus, in this case End notch flexure (ENF) specimen is been fabricated with the Teflon tape between the layers for mode II test specimen. In the mode II test, the ENF specimen is prone to indentation to study about the properties of the interlaminar strength at the prescribed conditions. Both the specimens are fabricated with and without carbon particles by adding it to the unsaturated polyester resin. The aim of this work is to introduce Bio char into basalt/polyester resin and to study about the interlaminar toughness property of the composite material. Thus, the study of ENF specimen will be examined and compared with different specimen and analysed. Thus the energy release rate and strain energy release rate will be studied [13-16].

\section{MATERIALS AND EXPERIMENTAL DETAILS}

\section{A. Materials}

Basalt unidirectional fabric (fig 1a) is a kind of good performance engineering material utilized as external bonding support material for various engineering purpose. Basalt unidirectional fabric of seven metre length was obtained from Arrow technical textiles private limited, Mumbai. The unidirectional basalt fabric is used as reinforcement and the unsaturated polyester resins is used as bonding materials and its play a major role in the preparation of composite materials. For curing the polymer is mixed with Methyl Ethyl Ketone Peroxide (MEKP) are used as a catalyst and Cobalt Naphthanete is as accelerator. This unsaturated polyester resin is thermosetting in nature and get cured exothermically. One of the biggest merit of this material is it provides adequate resistance to the water and is cheap in cost. In addition to that, the bio-char particles (fig. 1b) are added to the polymer resin for preparing hybrid polymer composites. The bio-char is made into a fine powder by means of sieve of size $100 \mu \mathrm{m}$. Thus the obtained biochar is used as constituent for making the specimen sample.

\section{B. Fabrication of Composites materials}

The Basalt fabric is first marked properly in order to cut the unidirectional fabric as its used to fabricate four different types of delamination specimens. Then the specimens are cut carefully with scissors as it's an unidirectional material so there are chances that the fabric might get disintegrated at the sides which may lead to poor fabrication of the specimen. After the pieces of Basalt fabric is been cut as per the required ASTM standard, then this fabric is synthesized using Unsaturated polyester resin. The resin of quantity 200 $\mathrm{ml}$ is being used to fabricate each set of delamination specimen. The catalyst MEKP (Methyl ethyl Ketone Peroxide) and cobalt naphthenate. These are the initiators used in activating the resin. For Each $200 \mathrm{ml}$ of polyester resin, $1 \mathrm{ml}$ of both catalyst is used. First an adequate amount of wax is been applied over the glass plates so as to prevent the sticking of the specimen with the plates. A fixed quantity of unsaturated polyester resin is being thoroughly mixed with MEKP and Cobalt Naphthenate until it should be a homogeneous mixer in round conical flask at a vigorous way in the atmospheric condition. The Teflon tape has been customized between the middle layers of composites. The specimen is made to cure at room temperature for 24 hours for the completion of polymerization.
Each specimen consists of nearly 8-12 pieces of basalt fabric according to the specimens to be synthesized. The Resin of quantity $200 \mathrm{ml}$ is been filled in the beaker, whereas MEKP and Cobalt naphthenate of amount $1 \mathrm{ml}$ is added to activate the Unsaturated polyester resin. The Basalt fabric is then placed carefully over the plates in a stack in order to make delamination specimen. Meanwhile in other hand the resin is mixed thoroughly in the glass beaker with a glass stirrer. The resin is then applied with a brush over the fabric layer one by one and in between the delamination tape is placed which would be having width of 50

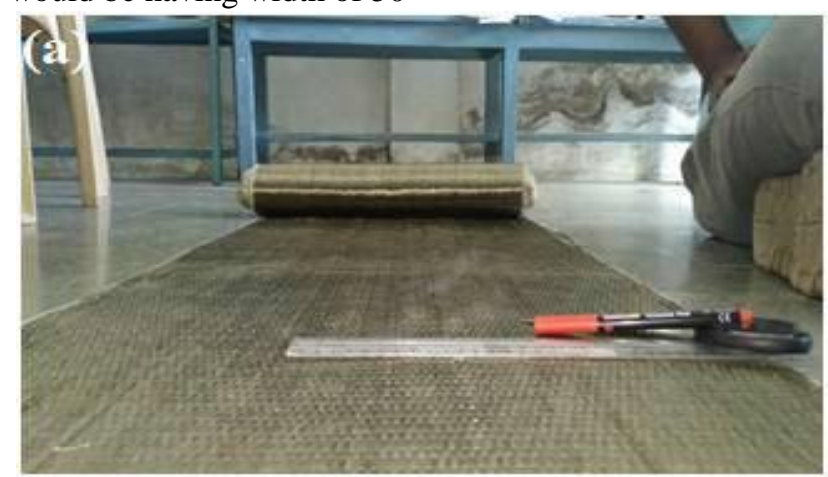

(b)
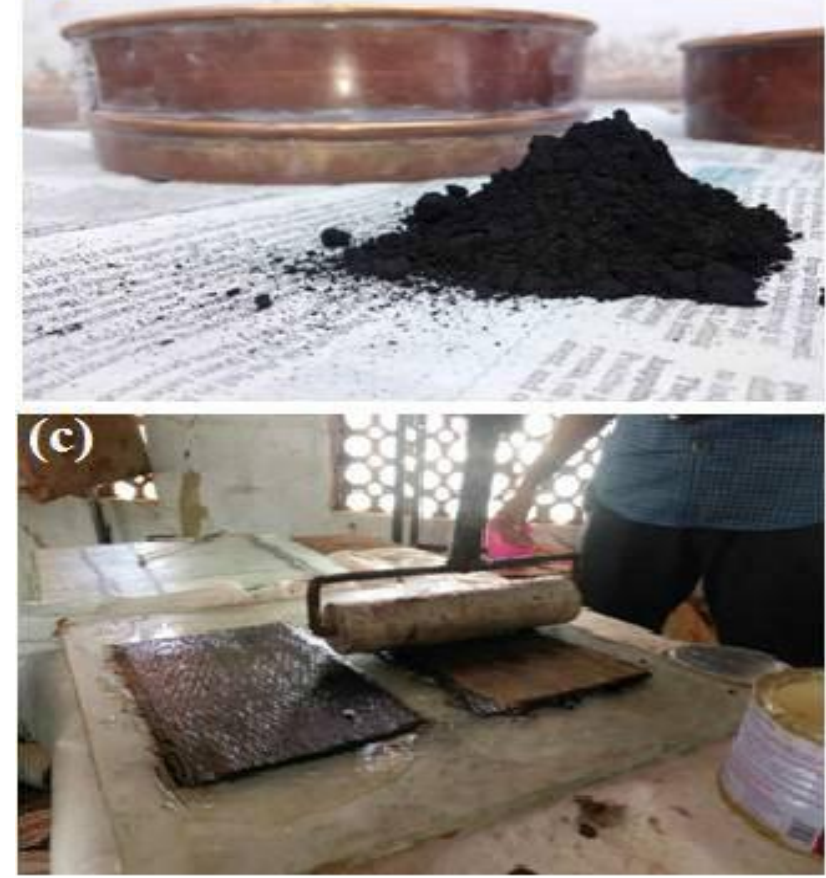

Figure 1. (a) Unidirectional basalt fiber, (b) biochar particles, (c) hand-layup process using roller.

Then after the Teflon tape is placed over the fabric the rest of the layer is then applied with the activated resin. The mixing of the catalyst and the fabric is an exothermic process. Then the rest of the fabric is placed over the Teflon tape material and the polyester resin is applied over and over each single layer. At the final layer the whole resin gets applied and then the specimen is synthesized using hand layup method (fig.1c) The hand roller is carefully moved through the delamination specimen and the resin gets squashed out of the specimen. After rolling through the other glass plate is placed over the specimen and a light weight is placed over that so the plate is synthesized properly. 
The specimen is left untouched for 1 day and then the delamination plate is thus obtained and the specimens are cut according to the ASTM dimensions. Then as the same for the specimen to be prepared with the biochar is fabricated. In this process the biochar is added with the unsaturated resin while the catalyst is been added. For each specimen $10 \mathrm{~g}$ of biochar is added, stirred properly and the specimen is fabricated.

\section{Tensile and flexural test}

Tensile test was performed in INSTRON universal tensile testing machine with a cross head testing speed of $10 \mathrm{~mm} / \mathrm{min}$. The gauge length of specimen is fixed as $50 \mathrm{~mm}$. Tensile test is conducted as per ASTM D3039 [17-18] standards with the specimen dimensions of $200 \mathrm{~mm} \times 20 \mathrm{~mm} \times 3 \mathrm{~mm}$. The end not flexure test is conducted in same testing machine with changing the load cell for flexure test. This test is performed as per ASTM standard for ENF specimens (fig 2).

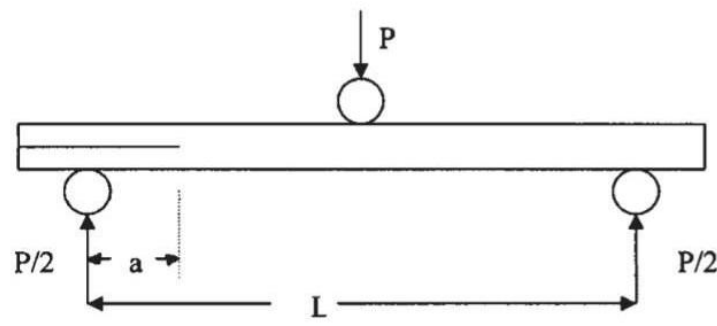

Figure 2. Schematic representation of ENF specimen [19].

\section{RESULTS AND DISCUSSION}

\section{A. Tensile strength}

Figure $3 \& 4$ shows the load displacement curve of 90 degree and 0 degree ply oriented basalt fabric reinforced polyester composites under the conditions of with and without addition of bio char particle reinforced polyester composites. The figure 3 , clearly shows that the load value maximum is occurred for 90degree ply orientation with addition of bio char to polyester. The minimum load value has on 90 degree ply orientation with addition of bio char. More over the highest displacement is occurred for bio char (BC) based polymer composites. When comparing the figure $3 \& 4$, maximum breaking load is occurred on 90degree ply orientation basalt fabric reinforced polyester composites compared to 0 degree ply orientation polymer composites. The main reason is good load transfer is occurred between fibre and matrix for 90 degree ply oriented composites, more over the load is acting along the line of action of fibre direction. At the same time poor load transfer is happen between fibre and matrix for 90 degree ply oriented composites due to the load is not acting along the line of action of fibre oriented direction. In 0 degree ply oriented composites has loading direction perpendicular to fibre reinforced. Acting load direction is main factor for obtaining high strength on materials.

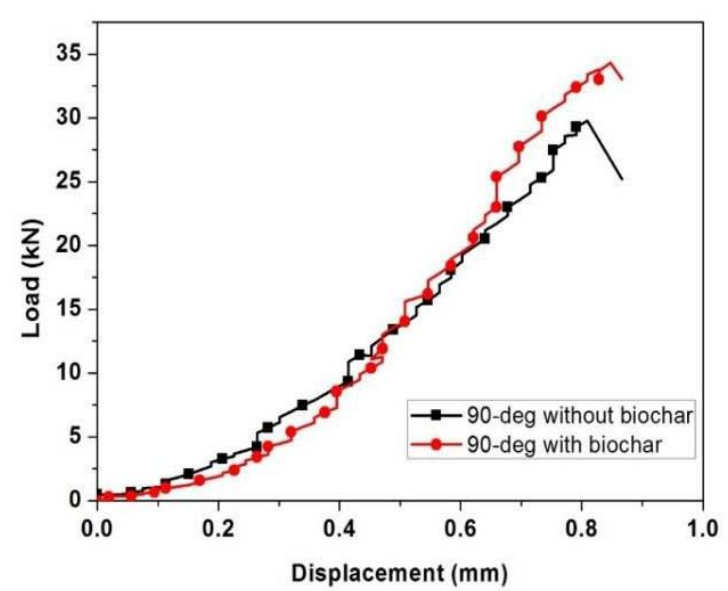

Figure 3. Load displacement curve of 90 degree ply oriented basalt fabric reinforced polyester composites with and without addition of bio-char particles.

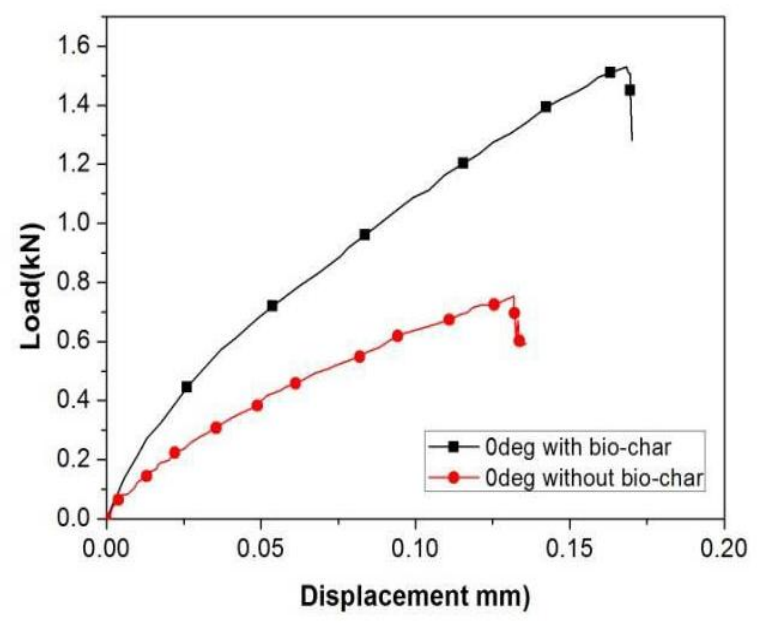

Figure 4. Load displacement curve of Odegree ply oriented basalt fabric reinforced polyester composites with and without addition of bio-char particles.

\section{B. Flexural strength of end notch specimens}

Figure $5 \& 6$ shows the tensile and flexural strength value of 90 degree and 0 degree ply oriented polymer composites with and without addition of bio char to polymer composites. The highest tensile and flexural strength is occurred on bio char based polymer composites due to good adhesion bonding. The lowest tensile and flexural strength is happen on basalt fabric reinforced polymer composites without addition of bio char particles. The main reasons for highest tensile and flexural strength is occurred on bio char based polymer composites due to good load transfer between fibres and matrix, good inter facial bonding between fibre and matrix. The bio char particles are act as a interlinking mechanism for fibre and matrix and also equally transfer the load between fibre and matrix. 


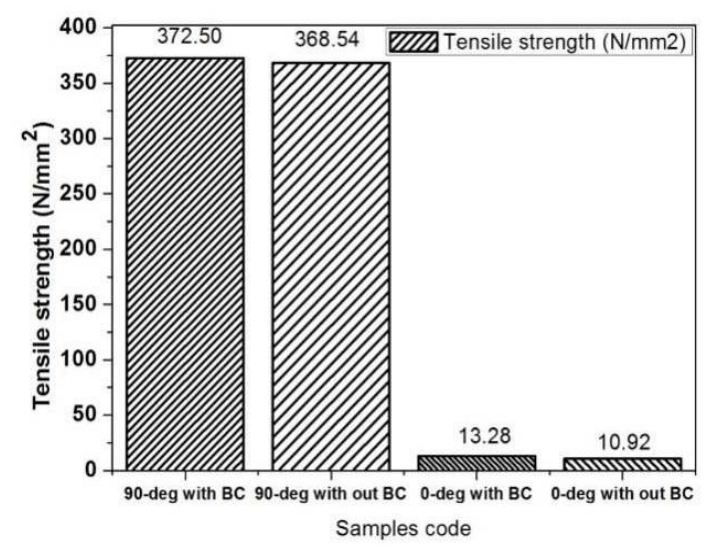

Figure 5. Tensile strength of $90^{\circ}$ and $0^{\circ}$ ply oriented basalt fabric reinforced polyester composites with $\mathrm{BC}$ and without $\mathrm{BC}$.

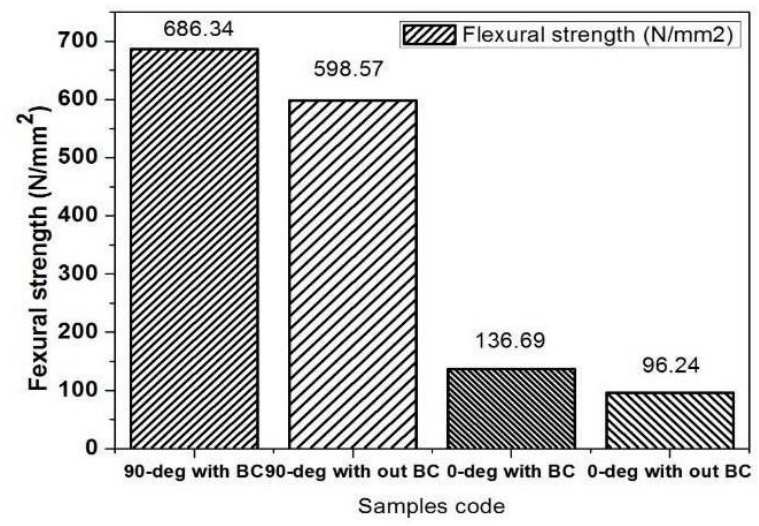

Figure 6. Flexural strength of 900 and 00 ply oriented basalt fabric reinforced polyester composites with $\mathrm{BC}$ and without $\mathrm{BC}$.

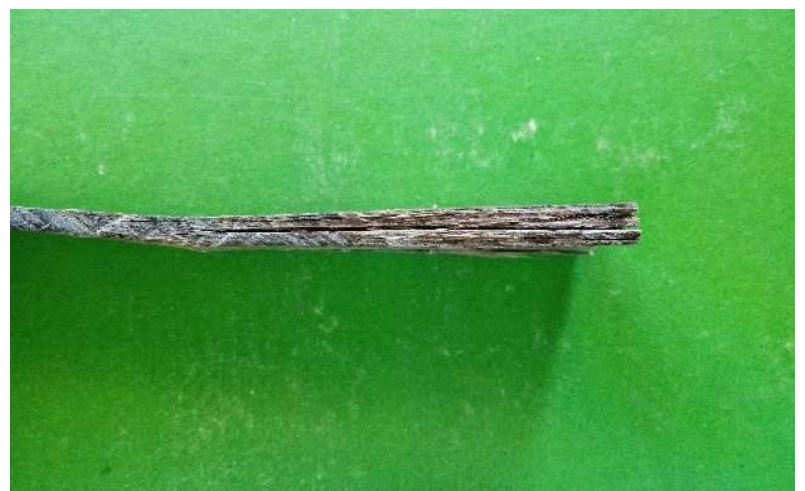

Figure 7. Photography image of delamination of 90degree ply inter-lamina specimen with bio char.

Figure 7 shows the photography image of delaminated polymer composites materials. During flexural test, the end notch of composites is delaminated due to crack initiated on the end of the composites. The crack opening displacement of layered composites image is shown on fig 8 and 9. Figure 8, shows the crack opening displacement (between two layer) of biochar filled on basalt polymer composites and figure 9 shows the crack opening displacement of basalt polymer composites. More crack opening displacement is observed on basalt polymer composites compare to hybrid polymer composites (basalt+biochar). The fiber bridge and less displacement of crack opening is observed on biochar filled basalt polymer composites. The main reason is biochar is acting as bonding with matrix between the two layers

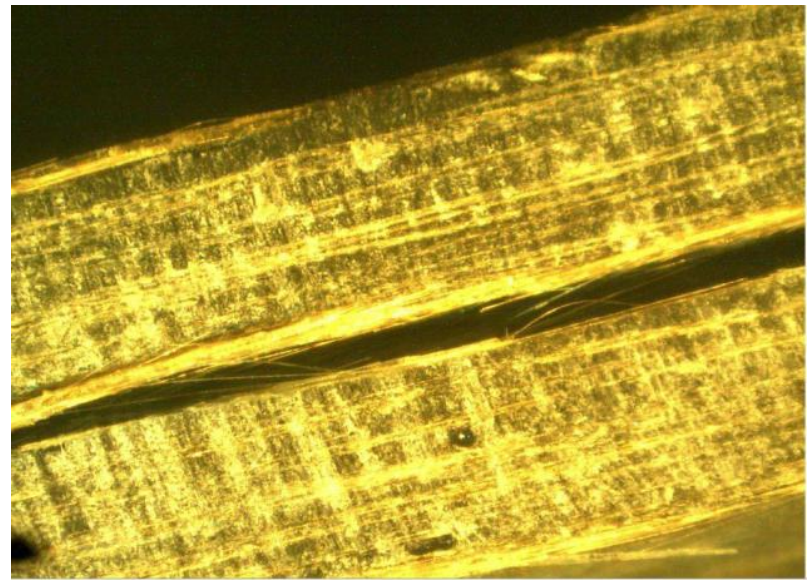

Figure 8. Optical microscopic image showing the fiber bridging effect in Basalt composite 900 with biochar specimen.

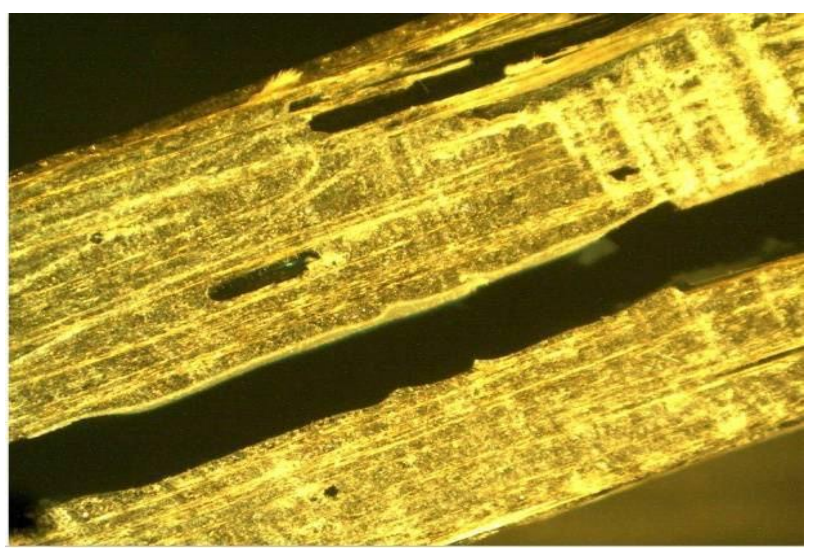

Figure 9. Optical microscopic image of 900 ply oriented without biochar.

\section{CONCLUSION}

The unidirectional basalt fabric reinforced polymer composites is successfully fabricated using hand layup techniques with 90 degree and 0 degree ply oriented conditions. The highest tensile and flexural strength is occurred on 90 degree ply oriented polymer composites due to good load transfer along the line of action of fibre direction. The lowest tensile and flexural strength is occurred on 0 degree ply oriented polymer composites due to load direction are acting on perpendicular to fibre direction. The bio char based polymer composites has highest maximum tensile and flexural strength due to better interfacial bonding between fibre and matrix. More over the bio char particles act as inter linking mechanism for fibre and matrix. Due to this reason better load transfer is occurred. The weak interfacial adhesion is happening between fibre and matrix for without bio char based basalt composites. The interlaminar fracture toughness of four different cases of basalt polymer composites has been investigated. The mode-I delamination fracture test was conducted under static loading conditions. The best fracture toughness is having on 90-degree ply- oriented polymer composites with addition of bio char to resin.

Published By:

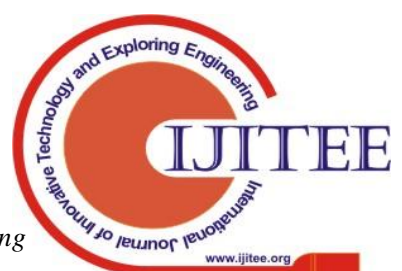




\section{REFERENCES}

1. U. Nirmal, B.F.Yousif, D. Rilling, P.V. Brevern, "Effect of betelnut fibres treatment and contact conditions on adhesive wear and frictional performance of polyester composites" Wear, 268,pp. 1354-1370, 2010.

2. R.B. Pipes, and N.J Pagano, "Interlaminar stresses in composite laminates under uniform axial extension" J. Composite Materials, 4, pp. 538-548, 1970

3. W. Yan, H.Y. Liu, and Y.W. Mai, "Numerical study of the mode I delamination toughness of z-pinned laminates" Composites Science and Technology, 63, p p . 1481-1493, 2003.

4. A.G. Castellanos, M.S. Islam, M.A.I. Shuvo, Y. Lin, and P.Prabhakar, "Nanowire reinforcement of woven composites for enhancing interlaminar fracture toughness" Journal of Sandwich Structures and Materials, 2016, DOI: 10.1177/1099636216650989

5. Hilding, E.A Grulke, Z.G. Zhang, and F. Lockwood, "Dispersion of Carbon Nanotubes in Liquids, Journal of Dispersion Science and Technology, 24, 1, pp. 1-41, 2003.

6. D.F. Adams, L.A. Carlsson and R.B. Pipes, Experimental characterization of advanced composite materials, Third edition, CRC Press, 2003.

7. M.S.ShamPrasad, C.S.Venkatesh, T.Jayaraju, "Experimental $\mathrm{p} p$ methods of determining fracture toughness of fiber reinforced polymer composites under various loading conditions" Journal of minerals \&materials characterization\& engineering, 10(13),pp 1263-1275,2011.

8. E.S. Greenhalgh, C. Rogers, P. Robinson, "Fractographic observations of delamination growth mechanism" In: 16th International Conference on Composite Materials, Japan; 2007.

9. Y. Gong, L. Zhao, J. Zhang, Y. Wang, N. Hu. "Delamination propagation criterion including the effect of fiber bridging for mixed-mode I/II delamination in CFRP multidirectional laminates" Compos. Sci. Technol, 151, pp. 302-9. 2017.

10. L. Zhao, Y. Gong, T. Qin, S. Mehmood, J. Zhang, "Failure prediction of out-of-plane woven composite joints using cohesive element" Compos Struct, 106, 407-16, 2013.

11. Y. Gong, L. Zhao, J. Zhang, N. Hu, "An improved power law criterion for the delamination propagation with the effect of large-scale fiber bridging in composite multidirectional laminates. Compos Struct, 184, 961-8, 2018.

12. J. Tao, C.T. Sun, “ Influence of ply orientation on delamination in composite laminates" J Compos Mater, 32(21),1933-47, 1998

13. Mehdi Yasaeea,et al., "Dynamic mode II delamination in through thickness reinforced composites" In book, Frac. Fatig. Fail. And Damage. Evaluation, 8, 2017, DOI: 10.1007/978-3-319-42195-7_13.

14. R, Rikards F.G. Buchholz, A.K. Bledzki, et al. "Mode I, Mode II and Mixed-mode I/II interlaminar fracture toughness of GFRP influenced by fiber surface treatment" Mech. Compos. Mater, 32(5), 1-24, 1996.

15. L. Zhao, Y. Gong, J. Zhang, Y. Wang, Z. Lu, L. Peng, et al. “A novel interpretation of fatigue delamination growth behavior in CFRP multidirectional laminates" Compos Sci Technol, 133 79-88, 2016

16. L. Peng, J. Zhang, L. Zhao, R. Bao, H. Yang, B.Fei. "Mode I delamination growth of multidirectional composite laminates under fatigue loading" J Compos Mater, 45(10), 1077-90,2011.

17. C . Uma Maheswari, K. Obi Reddy, E. Muzenda, M. Shukla. A. Varada Rajulu, "Mechanical properties and chemical resistance of short tamarind fiber/unsaturated polyester composites: Influence of fiber modification and fiber content" International Journal of Polymer Analysis and Characterization, 18, 520-533. 2013.

18. . K.Mayandi, N.Rajini, P.Pitchipoo, J.T. Winowlin Jappes, I. Siva, " Mechanical performance of Cissus quadrangularis /polyester composite" Materials Today Communications, 4, 222-232, 2015.

19. P.S. Sampath, V. Murugesan, M. Sarojadevi, G. Thanigaiyarasu, "Mode I and Mode II Delamination Resistance and Mechanical Properties of Woven Glass/Epoxy-PU IPN Composites" Polymer composites, 2008, DOI 10.1002/pc.20371

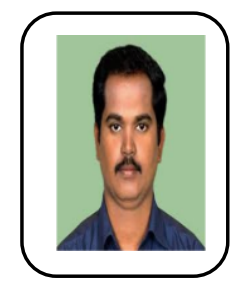

\section{AUTHORS PROFILE}

Dr.K.Mayandi received his B.E. (2007) in Mechanical Engineering and M.E. (2011) in Engineering Design from Anna University, Chennai and obtained his Ph.D (2016) from Kalasalingam University, Krishnankoil. $\mathrm{He}$ is working as an Associate Professor in the Schoo of Automotive and Mechanical Engineering at Kalasalingam Academy of Research and Education, Krishnankoil, Madurai, India. He worked as post doctorate fellow at Istanbul University, Turkey. His research interest on characterization of natural fibres and utilized the natura fibres as reinforcement with polymer composites materials for biodegradable applications. Recently focuses the research on fracture analysis of layered polymer composites materials and also involves the works on fabrication and testing of filament winding polymer composites tube for medium load applications areas. He has published 17 international journals and 2 book chapters published in Elsevier and Wiley publications.

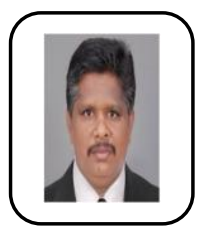

Dr.N.Rajini is working as Professor in the department of Mechanical Engineering in Kalasalingam Academy of Research and Education since 2004. He completed his $\mathrm{Ph} . \mathrm{D}$ in 2013 from Kalasalingam University. He completed his post-graduation in 2004. His area of interest is composite materials. He worked as post doctorate fellow at Ghent University, Belgium. He has international collaborative projects and researches. He published more than $100 \mathrm{SCI}$ and SCI-Expended articles.

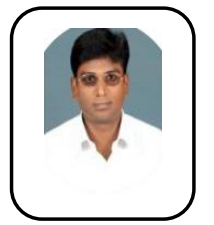

Dr.S.Rajesh is working as an Associate Professor and Head of the Department in the department of Mechanical Engineering at Kalasalingam Academy of Research and Education since 2004. He completed his Ph.D in 2014 from Kalasalingam University. He completed his post-graduation in 2004. His area of interest is machining studies in composite materials.. He published more than $20 \mathrm{SCI}$ and SCI-Expended articles. 